\title{
La noción de ciudadanía en el debate latinoamericano
}

\section{Carlos Sojo}

Director, Sede Costa Rica Facultad Latinoamericana de Ciencias Sociales. csojo@flacso.or.cr
Este artículo examina algunas de las contribuciones más significativas del debate contemporáneo latinoamericano sobre la cuestión de la ciudadanía. El tema ha adquirido importancia fundamental en la justificación de la política pública en todo el continente, sobre todo porque permite imaginar la cuestión social a partir de la integración activa de fenómenos económicos, sociales y culturales, y también abordar aspectos de la vida social —como los antagonismos de género, étnicos y ambientales — que plantean grandes desafíos a los regímenes políticos y a la estabilidad de los procesos económicos. Tras una sección introductoria, el artículo pasa revista a las bases conceptuales que originan la reflexión sociológica sobre la ciudadanía, examina las implicaciones del proceso de globalización en el análisis e identificación de los problemas asociados a la condición ciudadana, reseña algunos aportes que desde América Latina contribuyen a ampliar la capacidad explicativa y la utilidad práctica del concepto, y, por último, ofrece algunas consideraciones finales. 


\section{I}

\section{Introducción}

La revisión sociológica de la cuestión de la ciudadanía adquirió un nuevo impulso en el despertar europeo de los rigores autoritarios alentados por la Segunda Guerra Mundial. Este reconocimiento histórico es importante porque parece claro, como lo señala Escalante (1995), que pensar en torno a la cuestión ciudadana tiende a ser un acto cíclico, a menudo posterior a traumas políticos. En América Latina el renacimiento del debate sobre esta cuestión es contemporáneo con el período de transición democrática que se generaliza en toda la región desde mediados de la década de 1980. Por ello la primera afirmación que puede presentarse es que el tema de la ciudadanía está íntimamente ligado a la cuestión más general de la forma democrática de gobierno. Una vez establecidos los términos del pacto político prodemocrático, las sociedades inician un debate respecto de las características particulares de esa relación entre los individuos y el poder, entre el interés particular y las necesidades colectivas, entre "nosotros" y "los otros".

En el plano jurídico formal la cuestión de la ciudadanía se resuelve por la definición de un marco normativo de derechos y deberes de observación obligatoria para el conjunto de individuos abarcados en una comunidad histórico-territorial, denominada nación. Los derechos de ciudadanía aparecen así en la carta constitucional que, al mismo tiempo, definen los sujetos ciudadanos, y los portadores y beneficiarios de tales derechos y deberes.

En el orden político-ideológico, la ciudadanía se refleja como la autocomprensión dominante que se define como portadora del contenido integrador de la sociedad, a menudo en una afirmación que no admite validación empírica. Así, como señala Tenorio (1995), revisando los fundamentos excluyentes de la cultura cívica gestacional en los Estados Unidos "son ciudadanos los que son ciudadanos, los que actúan ciudadanamente". La ciudadanía es una afirmación de la comunidad, que se constituye en especial a partir de la noción del "otro". Se es ciudadano ante quienes no lo son. En el mundo de la guerra fría las divisiones ideológicas contribuyeron a facilitar la identificación ciudadana de comunidades a menudo sometidas a dominios políticos autoritarios: los socialistas enfrentados al imperialismo; los capitalistas al comunismo. Actualmente esta noción de ciudadanía parece corresponder con la noción formal de la "nacionalidad", porque es el denominador común que identifica a la comunidad ciudadana definida así como "nación". No obstante, persisten algunas consideraciones políticoideológicas que van más allá: las denominaciones religiosas tienden a crear comunidad más allá de los Estados nacionales, en el más dramático de los ejemplos. Las diversidades étnicas, por el contrario, sucumben ante la afirmación de una cultura dominante que se considera intérprete y garante de la ciudadanía.

La reflexión sociológica se fundamenta más en la dinámica de la integración social, o bien de la identificación de formas de exclusión dentro de entornos comunitarios que aparecen formalmente homogéneos. Como lo señala Jelin (1993, p.25) no se trata de la afirmación ahistórica de un conjunto de prácticas que definen la condición de ciudadanía, sino más bien de un ámbito relacional que alude a "una práctica conflictiva vinculada al poder, que refleja a las luchas acerca de quienes podrán decir qué, al definir cuáles serán los problemas comunes y cómo serán abordados".

En lo que sigue se pasa revista a algunos elementos de la discusión conceptual alrededor de la cuestión de la ciudadanía y sus implicaciones en el debate sobre lo político en América Latina. En primer lugar se analiza el concepto en su formulación clásica de la sociología inglesa de posguerra; en segundo lugar se examinan las implicaciones del proceso de globalización sobre una noción fuertemente anclada en la especificidad del Estado Nación, un locus en crisis en la era de la trasnacionalización y, por último, se señalan ciertas contribuciones basadas en la experiencia latinoamericana de la década de 1990. 


\section{II}

\section{Marshall y la noción clásica}

La concepción moderna de la ciudadanía se origina en el pensamiento del sociólogo británico Thomas H. Marshall, presentado por primera vez en una serie de conferencias en la Universidad de Cambridge en 1949 y publicadas al año siguiente bajo el título un tanto engañoso de Citizenship and Social Class. Digo engañoso porque en realidad dicho autor no se ocupa de analizar las posibilidades diferenciales de comprender los problemas de la ciudadanía desde una teoría de las clases sociales, puesto que más bien advierte que su propuesta en cierto modo responde a una "lógica" distinta. Marshall creía que las clases sociales se podían comprender sobre la base de dos procedimientos analíticos: una comprensión ciertamente weberiana según la cual la clase se fundamenta en la "jerarquía del status" sustentada por la ley y las costumbres, y una tipología de clases sociales que se origina en el producto del vínculo de las instituciones de propiedad y educación con el funcionamiento de la estructura productiva. En ambos casos, uno referido a la estratificación precapitalista y, el otro, a las formas más modernas derivadas de la industrialización, ciudadanía y clase apuntan a principios opuestos. 'Ciudadanía es un status asignado a todos aquellos que son miembros plenos de una comunidad. Todos los que posean dicho status son iguales con respecto a derechos y deberes... Clase social, por otro lado, es un sistema de desigualdad. Y también, como ciudadanía, puede basarse en un conjunto de ideales, creencias y valores' (Marshall, 1992, p. 18). ${ }^{1} \mathrm{La}$ argumentación subsecuente apunta a responder una interrogante central, relativa a la forma en que dos principios opuestos, "en guerra", florecieron en la Inglaterra de los tres siglos anteriores a la mitad del siglo XX. Aunque su propuesta es muy local, y puede ser acusada de múltiples carencias, en especial a la luz de las transformaciones globales de fin de siglo, la definición de Marshall sigue siendo interesante para reflexionar en torno a las posibilidades de consolidación democrática en sociedades que apenas empiezan experiencias de gobierno civil o en otras que, no habiendo sufrido los rigores de la guerra civil, sí han sentido

\footnotetext{
${ }^{1}$ En este artículo los textos entre comillas simples corresponden a citas que han sido traducidas del inglés por el autor.
}

los quebrantos de la crisis económica y de las no menos severas medidas adoptadas para estabilizar economías y reanudar el crecimiento.

Como se sabe, Marshall secciona la noción de ciudadanía distinguiendo tres elementos: civil, político y social. Le ha sido muy criticado el hecho de que encontró un desarrollo cronológico demasiado secuencial. Pero reconociendo que no se trata de desarrollos autónomos que ocurren una vez que ha concluido el proceso precedente, que los traslapos son evidentes, como él mismo lo advirtió, y sosteniendo que es posible que se produzcan avances e incluso retrocesos en cualesquiera de los elementos, puede continuarse con menos aprensiones la reconstrucción de la propuesta analítica de Marshall. Para él los derechos civiles están compuestos por "los derechos necesarios para la libertad individual": libertad de expresión, de pensamiento y religiosa, derecho a la propiedad privada y a la conclusión de contratos y el derecho a la justicia. Los derechos políticos se relacionan con el derecho a participar en el ejercicio del poder político, como miembro de un cuerpo investido de autoridad política o como elector de los miembros designados para integrar tales cuerpos. Los derechos sociales, finalmente, por su expansión y por la mayor flexibilidad en su diseño debido a los diferentes problemas que pueden confrontar, son definidos dentro de un rango que va "desde el derecho al bienestar y la seguridad económica hasta el derecho a compartir con el resto de la comunidad la herencia social y a vivir la vida como un ser civilizado de acuerdo con los estándares prevalecientes en la sociedad' (Marshall, 1992, p. 8).

La primera sensación es que mientras la afirmación e incluso la identificación de los derechos civiles y políticos no parece problemática, la tercera definición es extraordinariamente amplia. Por ello es preciso recordar que Marshall se ocupa de identificar las formas institucionales que se corresponden con el desarrollo de cada uno de estos derechos. En realidad, a esto dedica el resto del texto.

Así, las instituciones garantes y forjadoras de los derechos civiles son las cortes de justicia y el logro de los derechos de ciudadanía civil tiene mucho que ver con la consolidación de formas de administración de justicia y defensa que sean accesibles para todos 
desde el punto de vista económico. Los individuos son los sujetos primarios de estos derechos. A las cortes les compitió durante el siglo XVIII un papel fundamental en la defensa de la libertad individual, incluso ante los poderes públicos. En el campo económico, la libertad de trabajo - lo que Marshall denomina 'el derecho a seguir la ocupación de nuestra escogencia, en el lugar que elegimos, sujetos sólo a legítimas exigencias de entrenamiento técnico preliminar' (Marshall, 1992, p. 10) - fue fundamental para el desarrollo del capitalismo industrial, como lo reconociera Marx a mediados del siglo XIX. Para comienzos de ese siglo la libertad económica individual era considerada axiomática.

Entonces, piensa Marshall, se abre la posibilidad para el comienzo del período formativo de los derechos políticos. De lo que se trata no es de ampliar con nuevos derechos los logros de igualdad civil previamente alcanzados, sino hacerlos llegar a segmentos cada vez más extensos de la población. 'En el siglo dieciocho — recuerda Marshall- los derechos políticos eran deficientes, no tanto por su contenido, como por su distribución; deficientes, es decir, para las exigencias de la ciudadanía democrática' (Marshall, 1992, p. 12). Atados durante largo tiempo a la ciudadanía civil, los derechos políticos aparecían como el privilegio de una minoría poderosa de hombres blancos y acaudalados. Eran menos un derecho y más una "capacidad" de ciertos titulares de derechos civiles. Con el siglo XX los derechos políticos se autonomizan plenamente, al menos para los hombres, porque se empiezan a eliminar las restricciones pecuniarias para elegir y ser electos y se transita claramente hacia el voto adulto masculino universal. Fundamentados institucionalmente en los parlamentos y los concejos municipales, los derechos políticos son primariamente colectivos.

El origen de los derechos sociales se remonta a mediados del siglo XIX, con las políticas de protección a los pobres y de regulación de ingresos, pero con una particularidad semejante a la de los primeros derechos políticos. Las prestaciones sociales se otorgaban en forma de ayuda a personas que no eran ciudadanas; es decir, la ayuda social precursora de los derechos de ciudadanía social se originó en una asistencia que negaba la ciudadanía: 'El estigma ceñido a la ayuda para los pobres expresa un sentimiento profundo entre las personas que creen que aquellos que aceptan ayuda deben cruzar el sendero que separa la comunidad de los ciudadanos de la compañía proscrita de los destituidos' (Marshall, 1992, p. 15).
Esta aplicación "excluyente" de derechos sociales tiene en la América Latina contemporánea algunas expresiones nuevas, aunque ciertamente no institucionales como las que cuestionaba Marshall. Eso se verá más adelante.

Marshall reconoce que la aplicación y la expansión de los derechos así originados no habían contribuido hasta su época a una disminución sustantiva de la desigualdad. La respuesta que esboza está íntimamente ligada a su evaluación del desempeño de los derechos sociales en el siglo veinte. Las luchas sociales en ese siglo implicaron una profunda transformación de la aspiración de la ciudadanía social desde lo que eran intentos de combatir las privaciones sociales "elevando" el piso de la edificación pero dejando intacta la estructura. El propósito subsecuente es la transformación estructural del sistema, convirtiendo -en las palabras de Marshall- 'un rascacielos en un bungalow'. Tal transformación, sin embargo, se ve impedida por "límites naturales", entre los cuales destacan los procedimientos destinados a combinar propósitos de integración social con el sistema de precios de mercado. Marshall concluye que la ampliación de los servicios sociales no es necesariamente un medio para igualar ingresos, sino un instrumento de 'enriquecimiento de la substancia material de la vida civilizada'. En otras palabras el propósito de los sistemas de seguridad social no es la eliminación de las diferencias de ingreso, como en el caso de la supresión de las clases sociales así definidas, sino la eliminación de las diferencias de status social que pueden originarse, entre otras cosas, en desigualdades de ingreso. Otro límite está dado por la disponibilidad de recursos para satisfacer las expectativas crecientes de los individuos. Marshall reconoce que el 'blanco es el movimiento perpetuo hacia adelante, y el Estado podría ser siempre incapaz de mantener ese ritmo. Se sigue entonces que los derechos individuales deben subordinarse a los planes nacionales' (Marshall, 1992, p. 35). Esta limitación está condicionada por la fuerza diferencial de las demandas en competencia, y no significa que los derechos individuales queden en la indefensión: pueden defenderse en el ámbito judicial correspondiente, mientras los intereses colectivos se originan y ventilan en el parlamento y los gobiernos locales.

La argumentación se dirige por último a la afirmación de dos paradojas que ilustran la forma en que el principio del lucro individual, motor de la economía de mercado, ha podido convivir y desarrollarse con robustez frente a un principio contradictorio como el de 
la igualdad sustentado por el ideal de ciudadanía. En un párrafo tan lúcido como lírico, Marshall afirma que:

'Los derechos sociales en su forma actual conllevan una invasión del contrato por el status, la subordinación del precio de mercado a la justicia social, el remplazo de la libertad de comercio por la declaración de los derechos. ¿Pero son estos principios tan ajenos a la práctica mercantil de hoy, o más bien se encuentran ya engarzados con el sistema de contratos mismo? Pienso que es muy claro que lo están’ (Marshall, 1992, p. 40).

La solución de esta paradoja radica en que la institución de la ciudadanía propone derechos a los individuos pero impone también responsabilidades, las que se transforman no en un deber de sumisión a la voluntad absoluta del Estado, sino en una incitación permanente a orientar sus actos hacia el bienestar de la comunidad.

La otra paradoja deriva de la relación entre ciudadanos y partes contractuales en la economía de mercado. El lucro personal es la fuerza que rige el sistema liberal de contratos, mientras que la responsabilidad pública es el motor de los derechos sociales. La noción de ciudadanía en la concepción de Marshall apela a ambos principios. Postula que el ciudadano está llamado 'a responder el llamado del deber', al mismo tiempo que abre espacio a los motivos del interés individual.

En síntesis, pienso que la evolución de los derechos de ciudadanía desde sus orígenes civiles hasta los derechos sociales es el resultado de un enfrentamiento entre los ideales individualistas que impulsan el desarrollo del capitalismo y una buena parte de los valores igualitaristas que empujan la formación del sistema político democrático. Este enfrentamiento, que Wolfe (1980) atribuyó al liberalismo y la democracia, Marshall lo ve como el tránsito positivo hacia adelante de dos principios opuestos que funcionan armónicamente porque se autolimitan. Como señala Bryan Roberts en un ensayo inédito, Marshall definió ciudadanía como 'un principio de igualdad que coexiste, con dificultad, con la desigualdad social que resulta del juego de las fuerzas del mercado... Tiende a ver una ciudadanía plenamente desarrollada cuando se reducen las tensiones de la desigualdad social inducida por el mercado por medio del estímulo de la igualdad de oportunidades y la movilidad social' (Roberts, ed., 1998, p. 3).

\section{III}

\section{Ciudadanía y globalización}

El principal reto en la actualización del pensamiento de Marshall es, a mi parecer, la adecuación de sus propuestas a las condiciones cambiantes del mundo capitalista de la época posterior a la guerra fría. Su utilidad es innegable porque, como se sugiere en el prólogo de Robert Moore al texto de Marshall comentado, la idea de ciudadanía emerge en el mundo de la posguerra fría no como una expresión del liberalismo que pudo haberla originado en su versión de mitad del siglo XX, sino como manifestación de resistencia a un liberalismo presuntamente global y presuntuosamente universal, que no conoce como legítima la intervención del Estado en la regulación de las relaciones entre las personas y el mercado. Ese es en cierto modo el mejor de los legados de la noción marshaliana de ciudadanía. No hay ciudadanía en un mercado total; los consumidores no son ciudadanos porque carecen de derechos. Sólo les compete el deber de la realización del lucro individual.
En un ensayo complementario al estudio de Marshall, escrito 40 años después por Tom Bottomore, su colega de la London School of Economics, se hace un sugerente recuento de los efectos que las transformaciones globales más significativas de los últimos años pueden tener sobre las reflexiones marshalianas en torno a la ciudadanía (Bottomore, 1992).

Los acontecimientos globales obligan a hacer una distinción previa a la consideración de las tres áreas de derechos ciudadanos definidas por Marshall. Bottomore rescata la propuesta de otros autores de distinguir entre ciudadanía formal, definida como la membresía de un Estado Nación, y ciudadanía sustantiva, que implica tener derechos y capacidad de ejercerlos, con cierto grado de participación en los ámbitos público y privado, dentro de las tres áreas definidas por Marshall. Brubaker señala (citado por Bottomore, 1992) que la ciudadanía formal no es requisito previo para forma alguna de ciudadanía sustantiva, no 
es condición suficiente ni necesaria. No es condición suficiente porque, como las mujeres y los grupos étnicos subordinados lo saben muy bien, se puede pertenecer a una comunidad nacional y al mismo tiempo encontrarse excluido del disfrute de ciertos derechos acaparados por otros. No es condición necesaria porque se puede disfrutar de ciertos derechos sociales, civiles y hasta políticos aun sin ser parte de una comunidad nacional.

Esta contribución es trascendental porque permite sustraer el debate sobre el tema de la ciudadanía del entorno legal formalista y colocarlo en un plano estrictamente sociológico. Según Bottomore, la dimensión formal de la ciudadanía ha quedado en tela de juicio a partir de la expansión de tres fenómenos. Primero, la tendencia creciente a la migración no sólo desde los países periféricos a las potencias desarrolladas, sino entre polos de desarrollo dentro de las mismas periferias, que ha implicado demandas crecientes, sobre todo de derechos sociales, que los Estados no pueden simplemente desatender aunque quienes así exigen no sean ciudadanos formales. Segundo, una tendencia a la internacionalización del trabajo legal que exige facilidades de desplazamiento y de residencia legal a extranjeros. Y tercero, el problema más general de la relación entre residencia y ciudadanía, así como la definición de "la nación" como el locus exclusivo de la ciudadanía.

Los derechos ciudadanos sustantivos no se presentan de manera acumulativa y mecánicamente subsecuente como podría interpretarse, ciertamente con ligereza, en alguna lectura de Marshall. La transformación de los países socialistas dejó en claro que los derechos sociales podían desarrollarse en forma bastante libre en situaciones de extendida supresión de los derechos políticos y civiles. Por otra parte, la reforma democrática permitió una rápida recuperación de libertades civiles y derechos políticos en esos países y a la vez ha generado un paulatino aminoramiento de los logros de igualdad social en el sentido marshaliano, es decir, más allá de los ingresos. Por otro lado, aunque se tiene bastante información acerca de las deficiencias en el logro de objetivos vinculados con los derechos sociales, existen y han emergido nuevas áreas de carencia alrededor de las libertades civiles y los derechos políticos. La cuestión de la propiedad intelectual, a mi parecer, ilustra bastante bien un campo en el que la globalización empieza a confrontar seriamente intereses individuales y beneficios colectivos. Los acuerdos adoptados en materia de protección de propiedad intelectual en el marco de la Organización Internacio- nal del Comercio (OMC) han servido para la formación de derechos de alcance global sobre el conocimiento, su difusión y su uso comercial. Los titulares dominantes de tales derechos no son más individuos anclados a espacios nacionales, sino corporaciones que actúan en el escenario global. ${ }^{2}$ Sólo con propósitos ilustrativos, cabe señalar que es notorio, y motivo de denuncia internacional, cómo el conocimiento consuetudinario de los pueblos nativos sobre usos curativos de ciertas especies vegetales y animales termina convertido en derecho intelectual de las trasnacionales farmacéuticas. Como lo señala Shiva (2001, p. 166):

"La competencia es muy desigual, no sólo porque las empresas son poderosas y los pobres no lo son, sino porque las normas del libre comercio permiten a las empresas emplear la maquinaria de la nación-Estado para arrebatar recursos a la población, e impiden a la gente que reafirme y ejerza sus derechos".

La cuestión del desarrollo sostenible, por otro lado, abre un espacio donde no están claros los límites de la libertad individual, la importancia de lo nacional ni incluso la primacía de "lo humano" o "lo social" como factores de desarrollo. En este sentido Van Steenbergen (1994) señalaba el limitado desarrollo del análisis sobre la vinculación entre la cuestión ciudadana y "la problemática ambiental o ecológica". Postula que esta reflexión puede realizarse en tres sentidos: Primero, enfrentando la visión antropocéntrica de los derechos para incluir en ella los derechos de los animales o incluso de los seres humanos no nacidos, un elemento particularmente sensible en la lucha "por la vida" de las organizaciones antiabortistas. Segundo, en la aproximación ambiental a la cuestión ciudadana, haciendo hincapié en la "responsabilidad" de las personas por la defensa del mundo natural: este enfrentamiento con "la primacía de la sociedad sobre la naturaleza" (Ibid, p. 146) es sin duda un aspecto de importancia primordial en el diálogo Norte-Sur sobre las oportunidades de desarrollo, dado que supone una suerte de penalización de los usos sociales del territorio y una disminución de la soberanía de los Estados nacio-

\footnotetext{
${ }^{2}$ El Convenio sobre Derechos de Propiedad Intelectual Relacionados con el Comercio fue concebido y determinado por tres organizaciones: el Comité de propiedad intelectual, integrado por 12 corporaciones estadounidenses; la Federación japonesa de organizaciones económicas (Keidaren) y la Unión de confederaciones industriales y de empleados de Europa (Shiva, 2001, p. 170)
} 
nales sobre los recursos naturales. Y tercero, viendo la ciudadanía ecológica global como la resultante de una comprensión integral de recursos planetarios a partir de la combinación de opciones basados en el control y el cuidado de los recursos. La idea del control se relaciona con el desarrollo de los medios técnicos, políticos e institucionales para enfrentar las tareas del desarrollo sostenible. La idea del cuidado, por el contrario, apunta a mirar la tierra como un hábitat, una relación indisoluble basada en la igualdad de derechos de todas las criaturas vivas.

Lo mismo ocurre con las debilidades conocidas del proceso democrático que han sido magistralmente expuestas por Bobbio (1985) en su conocida obra $E l$ futuro de la democracia. Las limitaciones a la acreditación de individuos capaces de elegir; la exclusión de sectores de la población del derecho de representar intereses colectivos en la esfera pública; la homogeneidad creciente de las ofertas políticas, que disminuye la posibilidad efectiva de elegir entre opciones alternativas, y el acotamiento del ámbito de las decisiones que se someten a la acción electoral son algunas de las limitaciones con las que cotidianamente se enfrenta el ejercicio pleno de los derechos de ciudadanía política aun si entendemos, como propone Bobbio, la democracia en su sentido más estrecho como procedimiento para la toma de decisiones. Es en este ámbito donde la cuestión cultural ha implicado una redefinición en marcha de la diversidad de situaciones con las que la globalización confronta la visión tradicional de ciudadanía. Habermas (1994, p. 25) lo plantea como una visión de ciudadanía activa donde la organización de los individuos no origina un status legal ante el Estado, una credencial, puesto que:

'...los ciudadanos están integrados en la comunidad política como partes de un todo, esto es, de una forma tal que sólo pueden constituir su identidad personal y social en un horizonte de tradiciones compartidas y de reconocimiento institucional intersubjetivo'.

Alude así a rasgos de integración cultural que adquieren renovada importancia al buscar en la adaptación de la cuestión de los derechos a las transformaciones sociales y políticas del momento actual. Así, resulta esclarecedora la forma en que García Canclini (1995, p. 30 y siguientes) propone que la formación de identidades posmodernas está fundada en la transterritorialidad y el multilingüismo.
"Se estructuran —estas identidades - menos desde la lógica de los Estados que de los mercados; en vez de basarse en las comunicaciones orales y escritas que cubrían espacios personalizados y se efectuaban a través de interacciones próximas, operan mediante la producción industrial de cultura, su comunicación tecnológica y el consumo diferido y segmentado de los bienes".

Son, por lo tanto, patrones de integración que responden bien a este escenario global donde la relación con el mercado también da sentido de pertenencia y conforma comunidad social. Se trata entonces de comprender la globalización no solamente como un proceso de ampliación y generalización de intercambios bursátiles y comerciales o incluso — según han señalado Held y otros $(1999$, p. 28) — como un cambio en los lugares del poder y un distanciamiento de ellos respecto de los escenarios que experimentan sus efectos. Se propone la generalización de una idea de consumo que supone superar la lógica del individualismo posesivo (McPherson, 1981) en beneficio de "la apropiación colectiva, en relaciones de solidaridad y distinción con otros, de bienes que dan satisfacciones biológicas y simbólicas" (García Canclini, 1995, p. 53).

No obstante, puede pensarse que en lo que toca a los derechos políticos y civiles existe, como expresión del proceso de globalización, una tendencia a la uniformidad, a la definición de parámetros universalmente aceptables por encima de diferencias culturales o técnicas (como en el caso de los sistemas políticos). No sucede lo mismo respecto de los derechos sociales, que son los más controvertidos, primero por el alcance de las políticas sociales que generan en la actualidad y, segundo, por su definición misma atinente al efecto que deben tener en la estructura social.

De esta última apreciación desprende una argumentación central para la comprensión del fenómeno de ciudadanía, que no fue explorada por Marshall. La definición de los derechos es campo de lucha social, es arena de enfrentamiento político y de lucha de clases. Señala el profesor emérito de Sussex:

'Es evidente hoy, que lo que llamamos derechos de ciudadanía, que ahora considero, en un contexto más amplio, como derechos humanos, están en un proceso continuo de desarrollo profundamente afectado por cambiantes condiciones externas (especialmente en la economía), por la emergencia de nuevos problemas y la búsqueda 
de nuevas soluciones. Un factor principal más o menos constante de este proceso, lo he enfatizado, ha sido la antítesis entre la estructura desigual y las consecuencias del capitalismo y el clamor por mayor igualdad realizado por diversos movimientos sociales desde finales del siglo dieciocho. En el marco de esta oposición general de intereses y valores, el conflicto entre clases y partidos clasistas todavía desempeña un papel protagónico como fuente principal de políticas dirigidas a limitar o extender el ámbito de los derechos humanos, y de modo particular el grado de recursos colectivos requeridos para alcanzar lo que es definido como las necesidades básicas de todos los miembros de una sociedad en diversas etapas de su desarrollo' (Bottomore, 1992, p. 89).
En seguida Bottomore reconoce, un poco a regañadientes, que a fines del siglo XX algunos antagonismos no asociados a la producción (como el de los sexos o las etnias) adquieren una importancia central, aunque se apresura a indicar que muchos de ellos se originan parcialmente en desigualdades generadas por el capitalismo. Como veremos más adelante, esos antagonismos - que ciertamente no pueden comprenderse aislados de la esfera capitalista pero que no le son propios - resultan esenciales para comprender el debate contemporáneo en América Latina en torno al tema de la ciudadanía. Lo esencial de esta contribución de Bottomore, a mi modo de ver, es que rescata la centralidad de la acción social en la definición de lo que una sociedad entiende y defiende como derechos de ciudadanía en una circunstancia histórica particular.

\section{IV}

\section{América Latina y el tema de la ciudadanía}

El siguiente repaso de algunas contribuciones sobre el tema de la ciudadanía en América Latina parte por señalar que el renovado interés por él tiene mucho que ver con un proceso de reconciliación de los sectores políticos y académicos con la forma democrática del sistema político. Primero considerada expresión del dominio burgués, juego de apariencias para el totalitarismo de clase, la democracia se ha convertido en un valor indiscutible. No por ello, sin embargo, se ha abandonado la actitud vigilante y el señalamiento de las carencias que el novel proceso de democratización actual en la región presenta, en particular respecto del desarrollo social. La búsqueda de posibilidades de enfrentar esa nueva relación con la forma democrática ha propiciado el surgimiento de debates conceptuales que otrora no fueron considerados y que indudablemente han enriquecido el conocimiento de la realidad política de la región: el tema de la gobernabilidad, la cuestión de la sociedad civil y más recientemente la reflexión en torno a los derechos integrales en el marco del concepto de ciudadanía responden a ese propósito. El tema de la gobernabilidad se volvió relevante cuando las noveles democracias de la región empezaron a confrontar problemas cotidianos de gestión política en un horizonte marcado por demandas sociales crecientes y posibilidades limitadas de respuesta pública debido a la crisis económica y las políticas de estabilización y reforma centradas en la contención del gasto público. ${ }^{3}$ La cuestión de la sociedad civil ha permitido el desarrollo de nuevos debates alrededor de los sujetos sociales, debates especialmente relevantes después de la superación de una buena parte de los enfrentamientos político-militares que supusieron la localización de la relación Estado-sociedad en un ámbito cargado de determinaciones estructurales rígidas. El debate sobre la sociedad civil, aunque todavía muy centrado en aspectos taxonómicos, ha permitido reconocer la diversidad de procesos sociales y de posiciones subjetivas que articulan el movimiento social contemporáneo. $^{4}$

La idea de ciudadanía resulta adecuada para encarar los desafíos sociopolíticos de América Latina, en mi opinión, por dos razones centrales. En primer lugar, porque parte de un precepto de igualdad que concuerda con el propósito de la modernización democrática aunque se enfrente a los efectos de las reformas

\footnotetext{
3 Véase en Camou (2000) un análisis conceptual sobre gobernabilidad que es sensible a las peculiaridades del problema en América Latina.

${ }^{4}$ En el análisis de Biekart (1999) sobre la construcción de la sociedad civil en la Centroamérica de posguerra se sintetizan los rasgos más salientes del debate en América Latina a partir de la primacía que él observa del enfoque gramsciano, que enfatiza la lucha popular contra la hegemonía del mercado y del Estado.
} 
económicas y de la organización actual de la estructura productiva. En segundo lugar, porque como lo señala Roberts (ed., 1998) permite una aproximación integral a las cuestiones políticas, económicas y sociales, que posiblemente sea el único camino para hacer frente a un escenario futuro que parece privilegiar siempre el crecimiento de las empresas por sobre el bienestar de las personas. Es en cierto modo una posibilidad de comprender la democracia que no se relaciona sólo con las capacidades del Estado, por un lado, o con la generación de libertad y riqueza en el mercado, por otro. Es una oportunidad para reconocer el poder liberador de los derechos. Como señala Touraine (1995, p. 108):

"El tema de la ciudadanía significa la construcción libre y voluntaria de una organización social que combine la unidad de la ley con la diversidad de los intereses y el respeto a los derechos fundamentales. En lugar de identificar la sociedad con la nación, como en los momentos más relevantes de la independencia americana o de la Revolución Francesa, la idea de la ciudadanía da a la de democracia un sentido concreto: la construcción de un espacio propiamente político, ni estatal, ni mercantil".

El retorno a la ciudadanía se presenta entonces como una oportunidad para devolver a lo social la centralidad en el análisis del rendimiento de los sistemas políticos y económicos. En la diversidad de estudios latinoamericanos sobre el tema se distingue este propósito mayor. En particular, sin embargo, debe reconocerse que el tema de la ciudadanía ha sido poco abordado desde perspectivas integrales y se ha concentrado mucho más en el análisis de problemas de ciudadanías específicas, para plantearlo de algún modo. Los estudios nacionales abordan el tema haciendo hincapié en aspectos particulares, como la cuestión étnica, la cuestión cultural o los problemas políticos y sociales, pero no es usual encontrar análisis que ponderen la cuestión ciudadana en sus múltiples dimensiones en sociedades concretas. Esta ausencia relativa, hasta donde hemos podido indagar, de estudios integrales sobre las tres dimensiones de la cuestión ciudadana, puede ser un claro indicador de que los problemas de ciudadanía en América Latina están poco centrados en coordenadas geopolíticas y de Estados nacionales, porque se entiende que los procesos que generan esos problemas están también localizados en espacios transnacionales. Por ello es explicable la concentración de los estudios conocidos en aspectos vinculados a carencias particulares, a ciudadanías deficitarias o a ciertas subjetividades (por ejemplo, mujeres, etnias, jóvenes en espacios urbanos marginales, etc.). En estos casos, aun cuando se trata de análisis específicos, se reconoce la presencia explicativa de procesos que trascienden la espacialidad nacional. Dicho en otro sentido, el denominador común es que se trabaja con criterios de ciudadanía sustantiva y no de ciudadanía formal.

Desde diversas perspectivas analíticas, el tema de la ciudadanía se ha instalado en la reflexión sobre el desenvolvimiento político de las democracias latinoamericanas enfrentadas en algunos casos a las tendencias disgregadoras de una cultura de la globalización que ejerce fuerza centrífuga sobre la formación de identidades nacionales. Desde otras perspectivas se ha examinado el impacto de la transformación productiva en la consolidación de formas menos deficitarias de integración social y, de manera muy especial, se han estudiado las características de las experiencias de exclusión y de ciudadanías deficitarias, particularmente las relacionadas con la preocupación de los estudios de género por la evolución de las formas de discriminación contra las mujeres. No está demás señalar que una parte significativa del debate regional sobre la cuestión de la ciudadanía se origina en las contribuciones del pensamiento feminista latinoamericano a la comprensión de los límites de la participación plena de las mujeres en el ejercicio de los derechos ciudadanos que les corresponden.

La ciudadanía como identidad ha sido muy bien tratada, como hemos señalado antes, en la propuesta de García Canclini (1995) en su estudio sobre los consumos y las políticas culturales. Su argumentación parte del efecto de uniformación que la globalización ejerce sobre las identidades nacionales, las que representan un sentido de igualdad pero, sobre todo, una conciencia de la diferencia: "La ciudadanía y los derechos no hablan únicamente de la estructura formal de una sociedad; además, indican el estado de la lucha por el reconocimiento de los otros como sujetos de 'intereses válidos, valores pertinentes y demandas legítimas'." (Ibid., p. 21) En su argumentación García Canclini postula que la condición de consumidor es lo que integra cada vez más a las comunidades nacionales y que en el proceso de globalización esa misma condición se desprende de los vínculos originarios y se redefine: 
"Una nación, por ejemplo, se define poco a esta altura por los límites territoriales o por su historia política. Más bien sobrevive como una comunidad interpretativa de consumidores, cuyos hábitos tradicionales —alimentarios, lingüísticoslos llevan a relacionarse de un modo peculiar con los objetos y la información circulante en las redes internacionales. Al mismo tiempo, hallamos comunidades internacionales de consumidores - ya mencionamos las de jóvenes y televidentes- que dan sentido de pertenencia donde se diluyen las lealtades nacionales" (Ibid., pp. 49-50).

Al finalizar su reflexión el autor se interroga sobre los efectos de estos nuevos asideros de identidad para la formación de ciudadanías en lo que denomina la "participación creciente a través del consumo". Está consciente de que la racionalidad del beneficio individual que orienta el consumo no favorece necesariamente propósitos de solidaridad y bien común. No obstante, reconoce que muchos antagonismos que son centrales en los planos nacionales se desarrollan y ventilan en entornos más amplios e informados de lo que acontece a su alrededor. Propone entonces la restauración de una acción "política" para convertir a los consumidores en ciudadanos por medio de la redefinición del rol social del mercado y de la integración social por medio de "subsistemas culturales" que no se definen en la socioterritorialidad nacional.

El meollo de su propuesta estriba en la comprensión de los requisitos previos del tránsito de consumidores a ciudadanos y no, como podría afirmarse, en la supresión de los consumidores por un ciudadano utópico, altivo, que atiende el interés colectivo antes que el individual. Los requisitos de una sana articulación del consumo con el ejercicio de la ciudadanía son tres: i) acceso fácil a una oferta vasta, diversificada y representativa de los mercados de bienes y mensajes; ii) control de la calidad de los productos, basado en una adecuada información y capacidad de resistencia a la propaganda, y iii) "participación democrática de los principales sectores de la sociedad civil en las decisiones del orden material, simbólico, jurídico y político donde se organizan los consumos: desde la habilitación sanitaria de los alimentos hasta las concesiones de frecuencias radiales o televisivas..." (García Canclini, 1995, pp. 53).

Observo en la propuesta de García Canclini una preocupación correcta por la identificación de mecanismos de construcción de ciudadanía en un entorno que está dominado por relaciones de consumo (de bie- nes, servicios y símbolos) que han sobredimensionado la fuerza del individualismo y minimizado la importancia de la cohesión nacional. No obstante, puede indicarse que lo que aparece como explicativo de una situación cultural generalizada puede desarrollarse con mayores o menores matices en distintas dimensiones. Por ejemplo, es obvio que los flujos de comunicación, y por consiguiente la información disponible para orientar la gestión ciudadana de los consumos, son mucho mayores en zonas urbanas que en entornos rurales y aunque es cierto que la región se encuentra en un proceso intensivo de urbanización, algunos países continúan siendo predominantemente rurales, como los de Centroamérica. La creación de una cultura de la vida informal, resultante de la ampliación de redes no mercantiles de intercambio y producción, coloca a una proporción cada vez más importante de la población de las ciudades latinoamericanas al margen de la racionalidad de un consumo que, visto desde la lógica del capital, sólo atiende intereses individuales. La rigidez de los mercados de trabajo ha propiciado el desarrollo de formas de capital social que no relacionan las prácticas de producción y consumo con el lucro individual y el ideal de la competencia, sino más bien con prácticas de cooperación y redes de solidaridad, que crean beneficios colectivos mucho más que ganancias individuales (Pérez Sáinz, 1996). No se trata solamente de adscripción a flujos transnacionales alternativos, sino más bien de una estrategia local de formación de identidades sociales que permite la incorporación a las redes dominantes de la cultura transnacional.

Calderón, Hopenhayn y Ottone (1996) aportan a esta reflexión una propuesta de ciudadanía extensa que procura ubicar vínculos funcionales entre las exigencias del desarrollo económico y las necesidades de la integración social. Su contribución además plantea un tema central en la definición de los nuevos contornos de la ciudadanía sustantiva que se refiere a la construcción de identidades basadas en una comprensión no antagonista de la otredad. La ciudadanía extensa no se construye más en la afirmación de una identidad contraria a "los otros", sino de una identidad solidaria y cooperativa. En su propuesta la idea de ciudadanía adquiere "complejidad semántica" y contribuye a la ampliación de la noción de integración social y política en tres sentidos: Ante todo, "mayor equidad productiva" que alude a las capacidades de incorporación en los ejes dinámicos del crecimiento económico y que por ello modifican el acceso al disfrute de bienes y servicios. En segundo lugar, "mayor equidad simbóli- 
ca", entendiéndola, al igual que García Canclini, como la ampliación de las capacidades de obtener y manejar información, así como de acceder a las redes de consumos culturales; esta equidad simbólica es crucial para la formación de capacidades de diagnóstico acerca del déficit de ciudadanía, para la formación de derechos y para el cumplimiento de normas, y está además indisolublemente ligada a la transformación de los espacios públicos en la dirección del buen gobierno: más transparencia, más información y mayor capacidad de interpelación de los gobernantes por los gobernados. El tercer y último elemento que señalan los autores concierne a una mayor equidad en el ejercicio de los derechos en un plano de reconocimiento de la existencia de otras identidades.

Calderón, Hopenhayn y Ottone (1996) reconocen que los avances en los procesos de integración social considerados en el plano de ciudadanías extendidas no ocurren de modo secuencial y ordenado. Por el contrario, señalan que hay una tendencia a la ampliación de la equidad en el plano simbólico que mejora las capacidades ciudadanas de escrutinio de la gestión pública. Pero ese proceso de formación y ampliación de expectativas no se corresponde con una tendencia a la disminución de la equidad productiva. Esta misma paradoja puede reconocerse cuando, en la terminología marshaliana, el avance de los derechos de ciudadanía civil y política crea conciencia sobre las limitaciones de la ciudadanía social. Como lo plantean dichos autores:

"La asincronía entre una tendencia más lenta en los procesos de integración socioeconómica (promovidos por efecto de la transformación productiva y racionalización social) y una tendencia más intensiva de integración en el nivel simbólico y cultural (por efecto de la apertura política democrática y la industria cultural) podrá constituir, en los próximos años, un importante núcleo temático en la lucha por la ciudadanía en buena parte de las sociedades de la región" (Ibid., 1996, p. 78).

Está claro que una revisión contemporánea sobre la cuestión de la ciudadanía debe incorporar el efecto de contar con flujos de información y comunicación más avanzados que acercan a los individuos la posibilidad de reconocer y seleccionar opciones de política o de consumo, en mayor medida que en un pasado señalado por la centralización autoritaria de la información y el conocimiento. Además, la restauración del análisis sociológico de la ciudadanía debe reconocer un entorno macrosocial y macropolítico sujeto a profundas transformaciones, como resultado de la generalización de la forma democrática de gobierno en forma simultánea con un programa de reformas económicas que resitúa a las economías, las posiciones estructurales de los individuos y el papel del Estado frente al crecimiento y el desarrollo económico. Estos son elementos nuevos que, desde la perspectiva latinoamericana, se reconocen como primordiales para la restauración de la noción de ciudadanía.

Más allá de esas preocupaciones y más acá de la experiencia vital se halla un conjunto de reflexiones en torno a la ciudadanía, que parte ante todo de la necesidad de una reconstrucción semántica "desde abajo" y, después, de la denuncia de derechos cercenados y de ciudadanías deficitarias.

En un aporte para la "construcción desde abajo" de ciudadanía, Jelin (1993) entrega una interpretación del concepto anclada en dos consideraciones básicas: la construcción social de los derechos y el carácter "revolutivo" de los mismos, en la medida en que generan responsabilidades de conciencia colectiva. Jelin advierte que el derecho esencial es "el derecho a tener derechos", según lo rescata de la propuesta de Arendt (1973). Y más adelante afirma que esto es indispensable para el reconocimiento de la plasticidad de los derechos y de su posibilidad de instalarse en una lógica incrementalista.

La dinámica de construcción social de derechos y deberes tiene de particular en América Latina que se da en medio de experiencias de transición democrática y con prácticas socioculturales destinadas a preservar rasgos de identificación colectiva en el entorno político-autoritario. Por ello el desafío de la construcción de ciudadanía aparece asociada por un lado a la responsabilidad estatal de consolidación de instituciones democráticas y, por el lado de la sociedad, a la gestación de prácticas nuevas y la adecuación de las anteriores, autoritarias y solidarias, para hacerlas concordantes con los ideales democráticos y sus planos institucionales.

"Desde la perspectiva de la formación de sujetos, el tema es el aprendizaje de las expectativas recíprocas en los vínculos con las(los) otras(otros): ¿Qué derechos tengo? ¿Cuáles son mis responsabilidades? Este proceso implica un doble juego en el que simultáneamente reconozco cuáles son las responsabilidades del otro hacia mí (y mis derechos) y aprendo cuáles son mis responsabilidades hacia el otro. Proceso que no sólo implica este 
aprendizaje de expectativas y conductas responsables sino también cómo definir la amplitud del espacio de la responsabilidad de cada sujeto" (Jelin, 1993, p. 34).

Este proceso de identificación de derechos a partir de un juego de dilucidación de responsabilidades propias y ajenas es determinante en la reconstrucción feminista de la cuestión de la ciudadanía que, como hemos señalado, se encuentra en la base de la mayor parte de las exploraciones teóricas y empíricas alrededor de este concepto en la América Latina contemporánea. ${ }^{5}$ Las autoras Bareiro y Clough (1996, p. 29) indican que la aproximación feminista a la cuestión de la ciudadanía se ha centrado en dos consideraciones: primero, el diseño de estrategias para insertar a las mujeres en los espacios públicos con pleno reconocimiento de sus derechos tradicionales y específicos (como los relacionados con la sexualidad, el trabajo, la violencia); segundo, una exploración de las lógicas de la conquista de derechos, de la formación subjetiva (lo que implica revalorizar la agenda política), de la participación ciudadana y del tema del poder.

Las autoras citadas proponen revisar el origen del concepto de ciudadanía plena como un aporte a la aspiración del feminismo latinoamericano de alcanzarla. Centrándose en una propuesta rastreada hasta Talcott Parsons, destacan la importancia de identificar los mecanismos que gobiernan el proceso de inserción de grupos excluidos en el disfrute pleno de la ciuda- danía. Este proceso se puede dar por asimilación o por inclusión. Según señalan Bareiro y Clough, la asimilación supone la homogeneización del grupo y, en consecuencia, la incorporación se da una vez que los excluidos adquieren las características de los incluidos. La inclusión, por el contrario, acepta las diferencias de los miembros y los integra en su diversidad. Aunque las autoras reconocen la utilidad de esta distinción entre posibilidades de integración social para el debate sobre la diferencia, esencial para la cultura política feminista, no elaboran acerca de ella. Sin embargo, es evidente que uno y otro de los mecanismos señalados tienen consecuencias altamente diferenciadas.

Consideremos en este sentido algunos procesos contemporáneos. Las medidas de compensación social, por ejemplo, tienden a la igualación por ingresos, pero no desarrollan medios para eliminar otras desigualdades que impiden el disfrute de ciudadanías plenas a mujeres y hombres. La aceptación de la diversidad en los órdenes civil y político de la ciudadanía, como puede quedar de manifiesto en el proceso de incorporación de los pueblos indígenas a los sistemas políticos de elección y gobierno, no incluye aceptación respecto de sus derechos sociales. O como ocurre con las mujeres en el plano de la política, la aceptación en su diversidad de su derecho a elegir no implica necesariamente que haya la misma intención de inclusión respecto a su derecho de participar en el proceso de toma de decisiones y en las estructuras de poder.

\section{Consideraciones finales}

Pensar la política en clave de ciudadanía, originalmente una aspiración de analistas liberales, es hoy, especialmente en América Latina, una demanda política propiamente tal. Esto quiere decir que la ciudadanía, más que una práctica consolidada, es una aspiración social en una región donde los déficit de ejercicio pleno de

\footnotetext{
${ }^{5}$ Véase una muestra de las reflexiones en torno al tema de la mujer y la ciudadanía en la compilación de ponencias presentadas en el Taller "Mujeres, Participación Política y Ciudadanía", organizado por la Maestría Regional en Estudios de la Mujer (1997) de la Universidad de Costa Rica. En lo que en particular concierne a la exclusión de los derechos políticos, puede verse García Prince (1997).
}

ella son severos, más agudos para mujeres y etnias, pero generales. Las carencias no son sólo de derechos sociales, pero es evidente que la formación de responsabilidades colectivas para la construcción de sistemas sociales no excluyentes es requisito indispensable para la consolidación de la democracia. Dicho en otras palabras, el desarrollo democrático sin derechos sociales es posible pero no es sostenible.

Las carencias de otras formas del derecho ciudadano son notorias en sistemas políticos cada vez más monocromáticos y ajenos al escrutinio popular. La libre empresa o libertad económica, centro de los derechos civiles en el entorno social del capitalismo, con- 
tinúa siendo una condición elitista. Uno de los principales signos del presente es que aunque es posible que la reorganización productiva impuesta por la globalización no esté generando mayor exclusión absoluta, porque la pobreza extrema al menos no tiende a aumentar de manera generalizada, hay cada vez mayor evidencia de su capacidad para crear desigualdad y ello conduce a crear situaciones de exclusión. Los ciudadanos modelo de la globalización son los "hiper-ciudadanos", que no adscriben a identidades nacionales acreditadas por el Estado y que transitan en los flujos transnacionales del comercio, la información y el capital. Los demás quedan en una condición "preciudadana”, en la cual la identidad es producto de la carencia común y de la limitada participación en los beneficios más elementales de la pertenencia ciudadana: en lo civil, el derecho a la contratación libre no está más disponible para contingentes de población lanzados al desempleo permanente o al autoempleo de subsistencia; en lo político, sufren la invisibilidad como sujetos porque están fuera de las listas de electores o de candidatos; y en lo social enfrentan el hecho de que - hoy como ayer - claramente no hay automatismo en la relación crecimiento económico y bienestar social. En último análisis, sin embargo, la "hiperciudadanía" y la "preciudadanía" comparten una suerte de divorcio con lo público, cuando es sinónimo de lo estatal nacional. La primera porque los flujos de acumulación de bie- nes materiales y simbólicos ya no pasan por ahí, la segunda porque lo poco que todavía depende de las voluntades nacionales no la favorece.

La reconstrucción de la ciudadanía, por lo tanto, exige integración social en diversos planos. Nacional y transnacional, porque no se puede aspirar a la consolidación de identidades de aislamiento. La ofuscación de los nacionalismos, como queda de manifiesto en el desconcierto del Este europeo, es expresión de la imposición autoritaria de la ciudadanía formal. Las nuevas identidades pasan por el reconocimiento de uno mismo y el de los "otros" en el espacio nacional y fuera de él. La nueva reconstrucción exige también su instalación en coordenadas a la vez socioeconómicas y políticas: los derechos al bienestar no pueden ser ajenos a la libertad y ésta no existe en un ambiente de privaciones y de desesperada lucha por la supervivencia cotidiana. La ciudadanía plena de hombres y mujeres es integral, aunque todavía tiene sentido el examen segmentado de sus deficiencias.

Por último, toda aspiración reconstructiva de los ideales de ciudadanía debe partir del reconocimiento de su heterogeneidad semántica y de su connotación de constructo social. Es decir, la lucha por la ciudadanía es acción cotidiana permanente, espacio de conflicto y antagonismo social. La ciudadanía plena es la utopía y, como se sabe, nadie ha encontrado la isla de los sueños de Moro.

Bibliografía

Arendt, H. (1973): The origins of totalitarianism, Nueva York, Harcourt, Brace \& World.

Bareiro, L. y J. Clough Riquelme (1996): Nuevas voceras de la ciudadanía plena. Borrador para los debates de la plenaria del PMGL de la Unión Internacional de Autoridades Locales (IULA)/ Centro Latinoamericano de Capacitación y Desarrollo de Gobiernos Locales (Celcadel), realizada en Cochabamba, Bolivia, 14-16 de noviembre de1996.

Biekart, K. (1999). The Politics of Civil Society Building, Utrecht, Países Bajos, International Books.

Bobbio, N. (1985): El futuro de la democracia, Barcelona, Plaza y Janés Editores.

Bottomore, T. (1992): Citizenship and social class, forty years on, en T.H. Marshall y T. Bottomore, Londres, Pluto Press.

Calderón, F., M. Hopenhayn y E. Ottone (1996): Esa esquiva modernidad, Desarrollo, ciudadanía y cultura en América Latina y el Caribe, Caracas, Organización de las Naciones Unidas para la Educación, la Ciencia y la Cultura (UNESCO)/Nueva Sociedad.

Camou, A. (2000): La múltiple (in)gobernabilidad: elementos para un análisis conceptual, en Revista Mexicana de Sociología, año LXII, $\mathrm{N}^{\circ}$ 4, México, D.F., Universidad Nacional Autónoma de México (UNAM), Instituto de Investigaciones Sociales de la UNAM.
Escalante Gonzalbo, F. (1995): El problema de la ciudadanía. Moralidad, orden y política, Estudios Sociológicos, Vol. XIII, №39, México, D.F., El Colegio de México.

García Canclini, N. (1995): Consumidores y ciudadanos. Conflictos multiculturales de la globalización, México, D.F., Grijalbo.

García Prince, E. (1997): Derechos políticos y ciudadanía de las mujeres. Una vía género sensitiva y paritaria al poder y el liderazgo, San José, Costa Rica, Ministerio de Cultura, Juventud y Deportes, Centro Nacional para el Desarrollo de la Mujer y la Familia.

Habermas, J. (1994): Citizenship and national identity, en Bart van Steenbergen (ed.), The Condition of Citizenship, Londres, Sage Publications, Ltd.

Held, D. y otros (1999): Global Transformations. Politics, Economics and Culture, Cambridge, Polity Press.

Jelin, E. (1993): ¿Cómo construir ciudadanía? Una visión desde abajo, Revista Europea de Estudios Latinoamericanos y del Caribe, $\mathrm{N}^{\circ}$ 55, Amsterdam, Países Bajos, Centro Interuniversitario de Estudios y Documentación Latinoamericanos (CEDLA).

Maestría Regional en Estudios de la Mujer (1997): Taller: Mujeres, participación política y ciudadanía, San José, Costa Rica, Universidad de Costa Rica. 
Marshall, T. H. (1992): Citizenship and social class, en T.H. Marshall and T. Bottomore, Citizenship and Social Class, Londres, Pluto Press.

Marshall, T.H. y T. Bottomore (1992): Citizenship and social class, Londres, Pluto Press.

McPherson, C.B. (1981): La democracia liberal y su época, Madrid, Alianza Editorial.

O’Donnell, G. (1993): Estado, democratización y ciudadanía, Nueva Sociedad, $\mathrm{N}^{\circ}$ 128, Caracas, Editorial Texto.

Pérez Sáinz, J.P. (1996): De la finca a la maquila, San José, Costa Rica, Facultad Latinoamericana de Ciencias Sociales (FLACSO).

Roberts, B. (ed.) (1998): Ciudadanía y política social, Colección centroamericana de reestructuración, $\mathrm{N}^{\circ} 3$, San José, FLACSO.

Shiva, V. (2001): El mundo en el límite, en A. Giddens y W. Hutton (eds.), En el límite. La vida en el capitalismo global, Barcelona, Tusquets Editores.
Stavenhagen, R. (1998): Consideraciones sobre la pobreza en América Latina, Estudios sociológicos, vol. XVI, $\mathrm{N}^{\circ} 46$, México, D.F., El Colegio de México.

Tenorio, M. (1995): Estados Unidos: Ciudadanía y cultura en tiempos de desazón. El debate de los noventa, Estudios sociológicos, vol. XIII, N 39, México, D.F., El Colegio de México.

Touraine, A. (1995): ¿Qué es la democracia?, México, D.F., Fondo de Cultura Económica.

Van Steenbergen, B. (1994): Towards a global ecological citizen, en B. van Steenbergen (ed.), The Condition of Citizenship, Londres, Sage Publications Ltd.

Wolfe, A. (1980): Los límites de la legitimidad. Contradicciones políticas del capitalismo contemporáneo, México, D.F., Siglo Veintiuno Editores. 